\title{
"TRANSGREDINDO A NORMA": AS MULHERES BRASILEIRAS E A LUTA PELO DIREITO AO SUFRÁGIO
}

\author{
Luciane Campos ${ }^{1}$
}

\section{Resumo}

A conquista dos direitos políticos foi o resultado de uma longa e árdua luta que envolveu as relações de gêneros e entendida como mais uma conquista emancipatória para o sexo feminino e que dividia opiniões da sociedade. O presente artigo tem por finalidade apresentar uma breve discussão sobre o impacto social e político que a luta sufragista brasileira acarretou nas primeiras décadas do século XX e apresentar fatos e sujeitos que contribuíram para a conquista do voto em 1932. No Amazonas essa questão também estava presente e, assim como em todo o Brasil, era refletida especialmente através da imprensa. Em 1934, a primeira mulher política do Estado foi eleita: Maria de Miranda Leão.

Palavras-chave: Sufragismo; Mulheres; Política.

\begin{abstract}
The conquest of political rights was the result of a long and arduous struggle that involved gender relations and understood as yet another emancipatory achievement for women and that divided the opinions of society. The purpose of this article is to present a brief discussion on the social and political impact that the Brazilian suffrage struggle had in the first decades of the 20th century and to present facts and subjects that contributed to the winning of the vote in 1932. In Amazonas, this issue was also present and, as in all of Brazil, it was reflected especially through the press. In 1934, the state's first political woman was elected: Maria de Miranda Leão.
\end{abstract}

Keywords: Suffragism; Women; Politics.

\footnotetext{
${ }^{1}$ Doutoranda em História Social pela Universidade Federal do Amazonas. Pesquisa sobre História das Mulheres, feminismo e Gênero. E-mail: professoralucianecampos@gmail.com
} 
No Brasil do final do século XIX e décadas iniciais do XX, as mulheres passaram a lutar para ter direitos. Essas lutas, de carater emancipatório, permitiram muitas mudanças no comportamento feminino, possibilitando uma redefinição da mulher na sociedade brasileira e a conquista de diversos direitos civis e políticos. No tripé das conquistas está o acesso à educação básica e superior ${ }^{2}$, a profissionalização e trabalho remunerado e o direito ao sufrágio ${ }^{3}$ e à elegibilidade. $\mathrm{O}$ direito de votar e serem eleitas ${ }^{4}$ para cargos no executivo e legislativo representava para as mulheres a ideia de cidadania plena e reconheciam no voto um instrumento de conquista e igualdade de outros direitos, o que de fato promoveria a transformação de suas existências na realidade socioeconômica-cultural.

Constituiu-se objetivo central desse artigo apresentar de forma breve a luta sufragista feminina no Brasil no início do século XX, tomando como base discussões teóricas de importantes trabalhos sobre o tema já publicados pelo país e buscando agregar as informações que refeletem as especificidades locais. Tais informações fazem parte de uma pesquisa de doutoramento ainda na fase inicial acerca da temática. Embora esse não seja tema novo na historiografia nacional, no cenário local ainda há muitas lacunas a serem preechidas. Sabemos pouco sobre o movimento sufragista no Amazonas, sobre suas militantes e sobre a atuação das primeiras parlamentares no Estado. Auxiliou-nos ainda na metodologia de pesquisa o uso da imprensa de forma dual: como fonte, nos fornecendo os elementos necessários da investigação e como objeto, na medida em que nos interessa pensar como os periódicos reagiam às questões que envolviam a luta pela conquista do voto, entendendo que a imprensa "não apenas interfere nas questões políticas, mas em diversos setores da vida social, na articulação e disseminação de ideias, valores, referências, memórias, ideologias, modos de pensar e agir em sua historicidade"

As questões de raça/classe ficam evidentes na pesquisa quando concluimos que as primeiras brasileiras envolvidas nos Movimentos Feministas pertenciam às classes sociais mais favorecidas, eram brancas, com um bom nível de escolaridade e uma

\footnotetext{
${ }^{2}$ Às mulheres foi permitido o acesso ao ensino Superior pelo Decreto $\mathrm{N}^{\circ} 7.247$, de 19 de Abril de 1879 (Lei da Reforma Educacional).

${ }^{3}$ Como conceito, o Sufrágio é um dos principais institutos dos direitos políticos, o qual abrange tanto o direito de votar quanto o direito de ser votado. Comumente, as expressões "sufrágio" e "voto" são empregados indistintamente, como sinônimos. Entretanto, a doutrina estabelece a diferença entre os termos: o sufrágio é o direito, enquanto o voto é o exercício. Ver: SANTOS, Luiza Chaves. Sufrágio Feminino e democracia no Brasil. Monografia de conclusão do Curso de Direito. PUC/RIO, Rio de Janeiro, 2017. p.18. ${ }^{4} \mathrm{o}$ jus suffraggii e o jus honorum, como distinguiam os romanos.

${ }^{5}$ LEITE, Carlos Henrique Ferreira. Teoria, metodologia e possibilidades: os jornais como fonte e objeto de pesquisa histórica. ESCRITAS Vol. 7 n.1 (2015) ISSN 2238-7188 p. 3-17.
} 
profissão (especialmente médicas, professoras, dentistas, advogadas e escritoras) e um certo status social. Eram mulheres "que tinham acesso ao noticiário internacional e para quem a luta era uma demonstração de modernidade e progresso" "6. Faziam alianças e buscavam apoio político para "convencer" que suas reivindicações em relação à emancipação feminina eram sérias e extremamente necessárias para aquilo que se pretendia da sociedade do século XX. Nas palavras de June Hanner, "a questão do sufrágio pôde tornar-se um tópico mais vital para as feministas cultas que experimentavam um sentimento de frustração e privação política"7. Era notório para elas que sem o sufrágio não poderiam ser verdadeiramente iguais" ${ }^{8}$. Na definição de Gisela Bester, o sufrágio era a "chave de acesso" para as grandes mudanças". Ao analisar a importância do Voto - e em especial o voto feminino - numa democracia representativa, a autora observa que:

\begin{abstract}
a extensão do voto às mulheres significava e significa, ainda hoje, o acesso aos canais de decisão, executivos ou legislativos e, nesses, a fundamental possibilidade de serem tratadas questões femininas, de serem legislados assuntos referentes às mulheres, a partir da ótica das mulheres [...] Para as mulheres, votar e poder eleger seus pares, ou mesmo candidatos homens comprometidos com as causas femininas, constituiu e constitui o direito político por excelência, aquele que lhes permite ter maior força e legitimidade no encaminhamento, na justificativa e na defesa de projetos atinentes às mulheres e à sociedade em geral. ${ }^{10}$
\end{abstract}

No entanto, não foi uma luta fácil, muito pelo contrário, foi longa e árdua. Foram décadas de reivindicações, articulações feministas - envolvendo mulheres e também muitos homens que apoiavam a causa - e discussões políticas, que se iniciam antes mesmo da Proclamação da República ${ }^{11}$. Para June Hahner, a agitação política do período “fortaleceu o desejo das mulheres por seus direitos políticos e indiretamente forneceulhes não só argumentos adicionais pró-sufrágio, mas também oportunidade de empenharem-se por este direito"12. Mas é a partir de 1890, ano que ocorre a Assembleia

\footnotetext{
6 TOSCANO, Moema; GOLDENBERG, Miriam. A Revolução das Mulheres: um balanço do feminismo no Brasil. Rio de Janeiro: Revan, 1992.p.25

${ }^{7}$ HAHNER, June E. A Mulher Brasileira e Suas Lutas Sociais e Políticas: 1850-1937. São Paulo: Brasiliense, 1981.p.87

${ }^{8}$ HAHNER, June E. A Mulher Brasileira e Suas Lutas Sociais e Políticas. p.82

${ }^{9}$ BESTER, Gisela Maria. A luta sufrágica feminina e a conquista do voto pelas mulheres brasileiras: aspectos históricos de uma caminhada. Argumenta Journal Law, Jacarezinho - PR, Brasil, n. 25. p. 330333.

${ }^{10}$ BESTER, Gisela Maria. A luta sufrágica feminina e a conquista do voto pelas mulheres brasileiras: aspectos históricos de uma caminhada. p. 330-331.

${ }^{11}$ É importante dizer que o Brasil foi o primeiro país da America Latina a discutir a questão do Sufrágio feminino.

12 HAHNER, June. E. A luta pelos direitos da mulher no Brasil, 1850-1940. Florianópolis: Editora Mulheres/EDUNISC, 2003. p.160
} 
Constituinte, que a questão do sufrágio feminino passou a ser a pauta principal de luta e reivindicações das mulheres no Brasil.

É importante destacar que antes mesmo de lutarem para conqusitar esse direito de forma legal na Nova Costituição que estava sendo elaborada, ainda nos finais do século XIX, muitas mulheres de forma isolada, solicitaram seu alistamento eleitoral com base na Lei Saraiva que instituiu o título elitoral e garantia o direito de voto aos portadores de títulos científicos ${ }^{13}$. Entre as pioneiras, destacam-se as figuras das Cirurgiãs-dentistas Isabel de Sousa Matos, que no ano de 1885 requereu seu alistamento eleitoral na cidade de São José do Norte/RS, e a baiana Isabel Dilon que se apresentou como candidata à Constituinte mas não conseguiu alistamento. ${ }^{14}$

Acredita-se que inspirada na história de Isabel Dillon, a professora Josefina Alvares de Azevedo tenha escrito a peça Voto Feminino, em 1890. A comédia, apresentada uma única vez no Teatro 'Recreio Dramático', no Rio de Janeiro, teve a intenção de promover no público uma reflexão sobre as questões levantadas pelos grupos socias favoráveis e contrários ao sufrágio. Na peça, o debate familiar gira em torno das opiniões do patriarca da Família (Anastacio), sua esposa (Inês), o genro (Rafael) e a filha (Esmeralda) sobre o direito de voto feminino. Em uma das cenas, podemos conferir como a questão era cheia de conflitos ideológicos:
ANASTÁCIO (dirigindo-se a Rafael) - Meu genro, estamos perdidos, a revolução das saias entrou-nos porta adentro: é preciso reagir. A mulher votante! Com direito aos cargos públicos! Que Desgraça! Que calamidade! INÊS: - Calamidade é a de termos homens como o senhor que procuram aniquilar os nossos direitos em proveito da sua vaidade.
ANASTÁCIO (para Rafael) - o que diz a isso?
RAFAEL (atrapalhado, olhando para Ismeralda) - Eu...eu não digo nada.
ANASTÁCIO - Se o senhor tem aprovado a atitude delas.
ESMERALDA - Porque é justo meu pai.
ANASTÁCIO - Até a senhora! Está desejosa por votar e ser votada, ir ao parlamento, sobraçar uma pasta, andar de coupé e ordenanças! São assim todas as mulheres. Ah! Mas eu hei de ensiná-las! Agora é comigo. Senhor meu genro, venha daí. É preciso ser homem, ouviu? Ser homem! (empurrando-o na frente) Ande, mexa-se. ${ }^{15}$

Para Josefina, “o sufrágio realmente universal seria um símbolo poderoso a ser alcançado, pois trazia em si uma promessa de igualdade, de um tratamento mais justo

\footnotetext{
${ }^{13}$ Decreto n$^{\circ} 3.029$, de 09 de janeiro de 1881.

${ }^{14}$ Celi Pinto nos informa que Isabel Matos foi vitoriosa em sua cidade natal mas teve o direito suspenso quando tentou se alistar no Rio de Janeiro. PINTO, Celi Regina. Uma história do Feminismo no Brasil. São Paulo: Editora Fundação Perseu Abramo, 2003. p.15

${ }^{15}$ Cena sete da peça Voto Feminino. In: KARAWEJCZYK, Mônica. As filhas de Eva querem votar. Dos primórdios da questão à conquista do sufrágio feminino no Brasil (c.1850-1932). Tese Doutorado em História. Universidade Federal do Rio Grande do Sul, Porto Alegre, 2013. p.76.
} 
para as mulheres"16.

$\mathrm{Na}$ Constituinte de 1890, foi intensa a discussão entre os poucos deputados sensíveis à possibilidade da concessão do voto às mulheres e os que se posicionavam terrivelmente contra, usando de diversos argumentos para mostrar que o mundo político brasileiro não se abriria ao "sexo frágil". Vejamos um exemplo dessa assertiva:

\begin{abstract}
"Estender o voto à mulher é uma ideia imoral e anárquica, porque no dia em que for convertido em Lei, ficará decretada a dissolução da família brasielira. A concorrência dos sexos nas relações da vida ativa anula os laços sagrados da família"17
\end{abstract}

Karawejczyk destaca que a importancia dada à esse diálogo que se travou na Constituinte, "dá-se no sentido de que esta foi a primeira vez que o tema fora posto em discussão de modo mais sistematizado e por iniciativa dos próprios congressistas" ${ }^{\text {"18. As }}$ mulheres engajadas na luta sufragista de então, acreditavam que teriam o direito contemplado na nova Constituição. No entanto, no projeto ${ }^{19}$ publicado no decreto n. 914A de 23 de outubro de 1890, não havia qualquer menção sobre voto feminino. Durante a apreciação do projeto pela chamada Comissão dos $21^{20}$, algumas emendas foram propostas ao artigo 70, como a que permitia o voto "às mulheres diplomadas com títulos científicos e de professora, desde que não estivessem sob o poder marital nem paterno, bem como às que estivessem na posse de seus bens" ${ }^{21}$. A Emenda não foi aprovada recebendo apenas sete votos favoráveis do total de vinte e um congressitas e o projeto caminhou como estava para a próxima etapa na Constituinte. ${ }^{22}$

O texto final da Constituição de 1891 acabou não contemplando as mulheres mas também não trazia explícita nem a proibição e nem a permissão do direito ao voto. $\mathrm{O}$ texto considerou eleitores "os cidadãos maiores de 21 anos", que se alistassem na forma

\footnotetext{
${ }^{16}$ KARAWEJCZYK, Mônica. As filhas de Eva querem votar. Dos primórdios da questão à conquista do sufrágio feminino no Brasil. pag 82

${ }^{17}$ TOSCANO, Moema; GOLDENBERG, Miriam. A Revolução das Mulheres p.27

${ }^{18}$ KARAWEJCZYK, Mônica. As filhas de Eva querem votar. Dos primórdios da questão à conquista do sufrágio feminino no Brasil. pag 82. p.79

${ }^{19} \mathrm{O}$ projeto da Constituição foi elaborada pela chamada Comissão dos cinco, formada por: Saldanha Marinho, Rangel Pestanha, Antonio Luiz dos Santos Werneck, Américo Brasiliense de Almeida Mello e José Antonio Pedreira de Magalhães Castro; foi inspirada em três Constituições: Argentina, Estados Unidos e Suíça. In: KARAWEJCZYK, Mônica. KARAWEJCZYK, Mônica. As filhas de Eva querem votar. Dos primórdios da questão à conquista do sufrágio feminino no Brasil. pag 80

${ }^{20}$ Comissão especial para apreciação do projeto da Constituinte, eleita pelos congressistas e composta por um representante de cada estado incluindo o Distrito Federal

${ }^{21}$ Segundo nos informa Monica Karawejczyk, a emenda foi elaborada e apresentada pelos deputados Lopes Trovão (Distrito Federal), Leopoldo de Bulhões (Goiás) e Casemiro Junior (Maranhão). KARAWEJCZYK, Mônica. As filhas de Eva querem votar. Dos primórdios da questão à conquista do sufrágio feminino no Brasil. 87

${ }^{22}$ SOUTO-MAIOR, Valéria Andrade. O florete e a Máscara. Josefina Álvares de Azevedo. Dramaturga do Século XIX. Florianópolis: Mulheres, 2001. p. 76
} 
da lei ${ }^{23}$. Para Celi Pinto, “a mulher não foi citada porque simplesmente não existia na cabeça dos constituintes como um indivíduo dotado de direitos". O próprio termo “cidadão", segundo o senso comum da época, não se referia ao termo universal que abrange homens e mulheres, mas exclusivamente aos homens, reitera a autora. ${ }^{24}$

Muitas mulheres em várias partes do Brasil usaram dessa falta de clareza da Lei para requerer seu alistamento eleitoral. No entanto, o poder judiciário ficava livre para autorizar ou não esses pedidos e sempre optava pela recusa, prevalecendo a tradição conservadora, patriarcal e autoritária que relegava as mulheres à "um papel menor" na sociedade da época, fato que lhes causava muito constrangimento e revolta. Exemplo dessa assertiva é a trajetória empregada pela estudante de Direito Diva Nolf Nazário em busca do seu alistamento eleitoral em São Paulo, no ano de 1922. Nazário defendia que o voto feminino era constitucional e que era seu direito exercê-lo. Após seu processo caminhar longamente e ser recusado em vários setores, “com espanto e surpresa por ser uma mulher candidato" ${ }^{25}$, e recursos por sua parte, o parecer final do juiz eleitoral foi-lhe desfavorável. Esse fato fez com que Diva, que participava da Liga Paulista de Senhoras ${ }^{26}$, ficasse ainda mais atuante na luta pelos direitos políticos das mulheres. Um ano depois publicou o livro Voto Feminino e Feminismo ${ }^{27}$ descrevendo toda a sua luta e persistência em busca do seu alistamento eleitoral. O livro também aborda posicionamentos e argumentos variados em relação ao sufrágio feminino, presentes em artigos publicados na imprensa daquela época e copilados pela autora. Em um desses artigos publicados no jornal Gazeta de Batatais, ela escreveu:

Todos os dicionários estão acordes em dizer que um cidadão é um habitante de um Estado livre.

A mulher brasileira não será habitante de um Estado livre?

Diz-se sempre: "Todo o cidadão está sujeito às leis do seu país".

\footnotetext{
${ }^{23}$ É oportuno transcrevermos o artigo 70 da Constituição de 1891: "Art. 70 - São eleitores os cidadãos maiores de 21 anos que se alistarem na forma da lei. $\S 1^{\circ}$ - Não podem alistar-se eleitores para as eleições federais ou para as dos Estados: $1^{\circ}$ os mendigos; $2^{\circ}$ os analfabetos; $3^{\circ}$ as praças de pré, excetuados os alunos das escolas militares de ensino superior; $4^{\circ}$ os religiosos de ordens monásticas, companhias, congregações ou comunidades de qualquer denominação, sujeitas a voto de obediência, regra ou estatuto que importe a renúncia da liberdade individual. $\$ 3^{\circ}$ - São inelegiveis os cidadãos não alistáveis." (Constituição da República dos Estados Unidos do Brasil, de 24 de fevereiro de 1891). Disponivel em: http://www.planalto.gov.br/ccivil_03/Constituicao/Constituicao91

${ }^{24}$ PINTO, Celi Regina. Uma história do Feminismo no Brasil. p. 15-16

${ }^{25}$ SILVA. Lenina Vernucci da. Gênero e Poder: Diva Nolf Nazário na luta pelo voto feminino. Dissertação de Mestrado. UNESP Araraquara, 2014. p.22

${ }^{26}$ Filial da Federação Brasileira para o Progresso Feminino (FBPF) em São Paulo.

${ }^{27}$ Uma edição fac-similar foi publicada pela Imprensa Oficial do Estado de São Paulo em 2009. Na introdução do livro, Diva Nolf diz que a intensão ao escrevê-lo é a de "servir a nobre causa do feminismo que, no Brasil, há de ser brevemente vencedora, para a glória de nossa Pátria" (p.33)
} 
A mulher brasileira não estará, por acaso, sujeita às leis do Brasil? Ser-lhe a, por ventura, permitido matar e roubar sem incorrer nas penas estabelecidas para os homens?

Por que há de fazer exceção única e injusta quando trata de eleitores?

[...] Negar o direito de voto à mulher, é negar a utilidade da mulher em tantas ocupações onde só homem era visto antes. ${ }^{28}$

A decepção com a nova Constituição representou para as sufragistas uma "mola impulsionadora" para uma luta ainda mais intensa e organizada. Nesse sentido, destacamse dois importantes acontecimentos: a criação do Partido Republicano Feminino, em 1910, por Leolinda Daltro ${ }^{29}$ e a Federação Brasileira para o Progresso Feminino (FBPF) associação fundada por Bertha Lutz ${ }^{30}$, em 1922.

O Partido Republicano Feminino (PRF) tem destacada importância no movimento feminista do início do século XX. Organizado por mulheres, era um partido que mesmo sem direitos políticos, tinha o objetivo de representar os interesses femininos na esfera política. O PRF não defendia apenas o voto, mas a emancipação e a independência feminina ${ }^{31}$.

Mesmo com as ações do Partido Republicano Feminino, a questão do sufrágio feminino não foi mais discutida no Parlamento brasileiro até 1917, ano em que o deputado fluminense Mauricio de Lacerda, apresentou um projeto para incluir claramente as mulheres alfabetizadas como eleitoras. O referido projeto foi motivo de muita discussão entre os deputados no Parlamento, imprensa e sociedade de modo geral. A tentativa não teve sucesso. Mesmo assim, como defende Mônica Karawejczyk "apesar de não se

\footnotetext{
${ }^{28}$ NAZÁRIO, Diva Nolf. Voto feminino \& feminismo. São Paulo: Imprensa Oficial, 2009. p.41-44. Grifos no original. Optou-se por usar a ortografia atual.

${ }^{29}$ Segundo nos informa Celi Pinto, a motivação para Leolinda Daltro criar o Partido Republicano Feminino foi a recusa de seu alistamento eleitoral em 1909. Ela "era Professora e uma mulher muito diferente das de seu tempo. Criou 5 filhos sozinha. Indigenista, realizou uma cruzada a partir de $1895 \mathrm{em}$ defesa dos índios, contra o extermíninio e o autoritarismo da catequese". PINTO, Celi Regina. Uma história do Feminismo no Brasil, p. 18-19.

${ }^{30}$ Bertha Maria Júlia Lutz (1894-1976) era filha do cientista e pioneiro da Medicina Tropical, Adolfo Lutz, e da enfermeira inglesa Amy Fowler. Formou-se em Biologia pela Sorbonne. Em sua estadia pela Europa, tomou contato com a campanha sufragista inglesa. Voltou ao Brasil em 1918 e ingressou por concurso público como bióloga no Museu Nacional, sendo a segunda mulher a entrar no serviço público brasileiro. Ao lado de outras pioneiras, empenhou-se na luta pelo voto feminino e criou, em 1919, a Liga para a Emancipação Intelectual da Mulher, que foi o embrião da Federação Brasileira pelo Progresso Feminino (FBPF), tornando-se uma das principais líderes à frente do movimento feminino organizado no Brasil e umas das pioneiras da luta pelo voto feminino e pela igualdade de direitos entre homens e mulheres no país. Berta Lutz organizou o I Congresso Feminista do Brasil. Na Organização Internacional do Trabalho, discutiu problemas relacionados à proteção do trabalho feminino. Em 1929, participou da Conferência Internacional da Mulher, em Berlim. Ao regressar, fundou a União Universitária Feminina. Em 1932, criou a Liga Eleitoral Independente e, no ano seguinte, a União Profissional Feminina e a União das Funcionárias Públicas. Elege-se deputada em 1934,no Rio de Janeiro, como primeira suplente e tomou posse no ano de 1936.

${ }^{31}$ PINTO, Celi Regina. Uma história do Feminismo no Brasil, p. 18.
} 
conhecer as motivações que levaram Lacerda a propor a inclusão feminina no pleito eleitoral, seu projeto parece ter dado um novo alento ao tema do sufrágio feminino, tanto na imprensa como no Plenário",32.

De caráter altamente elitista e intelecutual, a Federação Brasileira pelo Progresso Feminino ${ }^{33}$, fundado por Bertha Lutz, era a maior expressão do feminismo nas décadas de 1920 e 1930, considerada a mais importante e também a mais conhecida organização em defesa dos direitos da mulher. Suas lutas estavam relacionadas principalmente com as questões que envolviam a instrução, o voto e a profissionalização. A FBPF reunia mulheres de várias profissões e tinha núcleos em vários Estados. Formavam alianças, buscavam apoio social e político aproveitando-se do prestígio social das mulheres que faziam parte do grupo. "Tratava-se de negociar e se aliar a tais poderes, ao invés de contestá-los. Esta atitude, que pode ser interpretada como conservadora, na verdade facilitou conquistas feministas, como o voto" ${ }^{34}$. Segundo Karawejczyk, o feminismo apregoado por Bertha passou a ser identificado, à posteriori, como "bemcomportado" e/ou "tático". Contudo, na época da sua aparição no espaço público brasileiro, ela foi identificada como representante de um "bom" feminismo deixando entrever que haveria outros, perigosos, que deveriam ser evitados ${ }^{35}$.

No Amazonas, a criação da Federação Amazonense pelo Progresso feminino, criada em 13 de Dezembro de 1932, pela Professora e farmaceutica Raymunda Chevalier, reunia importantes nomes do meio social manauara e articulava-se à luta nacional através da FBPF ao buscar alianças políticas locais para apoio e defesa nas causas femininas.

$\mathrm{Na}$ contramão do feminismo sufragista bem comportado, algumas lideranças feministas condenavam as estratégias usadas pelas militantes do movimento e no descrédito da eficácia do voto para a emancipação feminina. Entre essas lideranças estão Maria Lacerda de Moura e Isabel Cerruti. Seu feminismo, caracterizado como anarquista,

\footnotetext{
${ }^{32}$ KARAWEJCZYK , Mônica. "O voto e as saias": as repercussões do projeto Lacerda sobre o alistamento feminino (1917). Revista Altos e Baixos, 2015.p.72. Disponível em: http://revistadigital.jfrs.jus.br/revista/index.php/revista_autos_e_baixas

${ }^{33}$ Teve como sua entecessora a Liga para a Emancipação da Mulher, criada em 1919 também por Bertha Lutz.

${ }^{34}$ MOURELLE, Rodrigo Cavaliere et al. A Federação Brasileira pelo Progresso Feminino e o governo de Getúlio Vargas na década de 1930: estratégias e paradoxos do movimento feminista no Brasil. Colóquio Internacional Gênero, Feminismos e Ditaduras no Cone Sul. Universidade Federal de Santa Catarina - de 4 a 7 de maio de 2009

35 Aqui a autora utiliza expressões de (Céli Regina Jardim PINTO, 2003) e (Rachel SOIHET, 2006). KARAWEJCZYK, Mônica. O Feminismo em Boa Marcha no Brasil! Bertha Lutz e a Conferência pelo Progresso Feminino. p. 01;
} 
defendia que a emancipação da mulher não estaria vinculada à igualdade de direitos civis e políticos, mas sim à libertação dos preconceitos sociais já cristalizados naquela sociedade, frutos do sistema capitalista e patriarcal brasileiro ${ }^{36}$.

É salutar destacar ainda que na historiografia do movimento feminista o movimento sufragista não está isento de críticas no que se refere aos caminhos traçados na luta pelos direitos das mulheres. Para Branca Moreira Alves a conquista do direito ao voto não modificou a condição feminina no Brasil, "pois o evento em si não foi capaz de criar uma autoconsciência que as fizesse questionar a sua própria inferiorização social e as relações de dominação nas quais estavam inseridas" ${ }^{37}$, ou que o movimento sufragista brasileiro fez-se, em grande parte, conservador, para adaptar-se à uma sociedade atravessada por valores e relações patriarcais ${ }^{38}$ pois evitava contrapor-se à sociedade e à família, no intuito de se tornar aceito e respeitado pelas elites governantes ${ }^{39}$, diferentemente das estratégias, muitas vezes violentas, como as adotadas pelas suffragettes inglesas, por exemplo.

\section{A luta sufragista e a imprensa}

Convém destacar que a possibilidade dos direitos políticos femininos horrorizava muitos brasieliros, homens e mulheres, "não apenas pela ideia incômoda de mulheres eleitoras mas também o espectro de mulheres políticas que excitava a imaginação masculina" 40 . Outro ponto importante, é que em uma sociedade fortemente patriarcal como no caso da brasileira, as mulheres tinham papéis e lugares bem definidos dentro da sociedade em que viviam, eram limitadas por uma mentalidade conservadora e tradicional e quase sempre sofriam sujeição masculina. Tinham uma "missão" estabelecida e seu dever era cumpri-la com esmerada dedicação e abnegação: ser esposa e mãe, funções

\footnotetext{
${ }^{36}$ MANCILHA, Virginia Maria Netto, Vozes femininas: um estudo sobre a Revista Feminina e a luta pelo direito ao voto, ao trabalho e à instrução. Dissertação de mestrado - UNICAMP, 2012; Nesse viés de pensamento temos os trabalhos de Miriam Leite e Samanta Mendes que pesquisaram sobre a trajetória dentro do movimento feminista de Maria Lacerda de Moura e Isabel Cerruti, respectivamente. VER: LEITE, Miriam Moreira. Outra face do feminismo: Maria Lacerda de Moura. São Paulo: Ática, 1984; MENDES, Samanta C. "O feminino no Anarquismo: as mulheres anarquistas em São Paulo na Primeira República (1889 -1930).” Anais do XIX Encontro Regional de História: Poder, Violência e Exclusão. ANPUH/SP - USP. 08 a 12 de setembro de 2008;

37 ALVES, Branca Moreira. Ideologia e feminismo: a luta pelo voto no Brasil. Petrópolis: Vozes, 1980.p.155.

${ }^{38}$ SOIHET, Rachel. "Transgredindo e conservando, mulheres conquistam o espaço público: a contribuição de Bertha Lutz. Labrys-estudos feministas. Brasília, v.2, nº 1, julho-dezembro 2002.

${ }^{39}$ HAHNER, June. A luta pelos direitos da mulher no Brasil, 1850-1940. p. 366

${ }^{40}$ HAHNER, June E. A Mulher Brasileira e Suas Lutas Sociais e Políticas. p. 78
} 
sociais tidas como "naturais à realização da alma feminina"41 e extremamente valorizadas. Sendo a educação feminina destinada para este fim, as mulheres eram preparadas socialmente para desempenhar da melhor maneira possível as atribulações decorrentes do casamento, dos cuidados com a casa e principalmente com a educação dos filhos, para quem elas deveriam ser o mais perfeito dos exemplos na transmissão dos valores e da educação.

Como sabemos, as mudanças no comportamento feminino desencadeadas pela inserção das mulheres no espaço público' bem como a luta feminina/feminista em prol de seus direitos por educação, trabalho remunerado, voto e etc, incomodou a sociedade porque implicava, segundo os preceitos conservadores, numa "grave ameaça à ordem estabelecida"42. "Permitir", então, tais avanços femininos resumia-se em aceitar mudanças na estrutura patriarcal há séculos estabelecida.

Dessa forma, as mulheres envolvidas na luta emancipacionista enfrentavam o forte conservadorismo da sociedade, não só por parte dos homens, mas também de muitas mulheres defensoras da continuidade da supremacia do papel tradicional da mulher e viam como transgressoras da ordem e da família àquelas que contestavam a sua condição social de "Rainha do Lar". No que se refere ao movimento sufragista em especial, muito se falava das "tantas ameaças" que ele oferecia à sociedade, para a família e para as próprias mulheres. É salutar destacar que a aversão ao voto feminino não vinha somente dos homens mas também das mulheres que não tinham a pretensão de participar da política e criticavam as que defendiam.

Através da imprensa estas pessoas manifestavam seus posicionamentos, davam opiniões e consequentemente criavam representações femininas ideais, de acordo com as normas de condutas vigentes na sociedade. Devemos lembrar que na primeira República os jornais e revistas constituíam-se como os principais meios de propagação de ideologias no período e como importantes agentes na construção de representações.

As questões relacionadas à emancipação feminina, incluíndo o tema do sufrágio, sempre estiveram presentes nas publicações jornalísticas da grande e da pequena imprensa por todo o país. Na maioria das vezes, as publicações faziam chacotas e buscavam ridicularizar a luta feminina/feminista; outras vezes, noticiavam as estratégias,

\footnotetext{
${ }^{41}$ BORELLI, Andrea. "A Rainha do Lar". A esposa e a mãe perante a legislação brasileira. 1830-1950. Anais do XVIII Encontro Regional de História - O historiador e seu Tempo. ANPUH/SP - UNESP/Assis, 24 a 28 de julho de 2006.

${ }^{42}$ SOIHET, Rachel. Abaixo as mulheres. In: Revista Nossa História, ${ }^{\circ}{ }^{03}$. janeiro de 2004.
} 
lutas e conquistas femininas. Eram temas que sempre promoviam acaloradas discussões as quais muitas vezes envolviam grande parte da sociedade, principalmente os representantes do sexo masculino. Esse intransigente comportamento dos homens e da imprensa tem sua justificativa: ver uma mulher assumir uma cadeira na tribuna pública era simplesmente o pior e o mais incômodo dos acontecimentos da época pois "voto não se compatibilizava com o mundo dos sentimentos e do lar e marcava uma fissura definitiva na esfera masculina" ${ }^{43}$. Ou ainda, entendiam que a "mulher não tinha liberdade em relação ao marido para formar a sua própria opinião"44. Segundo o pensamento dos contrários aos direitos políticos femininos, a política deveria ser território exclusivo dos homen dado a incompatibilidade da natureza feminina com as atividades políticas. Como observou Perrot, a entrada das mulheres na política não é normal em nenhum lugar, quer se trate dos partidos, do legislativo ou do executivo ${ }^{45}$, pois para a sociedade da época, a política é uma profissão de homens, concebida e organizada no masculino.
Em seus ritos, em seus ritmos, em seus horários, em suas formas de
sociabilidade, em sua apresentação de si, que molda também a expectativa do
público, eventualmente decepcionado por ser representado por uma mulher. ${ }^{46}$;

Adversários do voto feminino declaravam que, com ele, se teria decretada a dissolução da família brasileira. Abaixo temos um exemplo de uma das publicações do Jornal $O M a l h o^{47}$ que se mostra contrariado com o projeto do deputado Mauricio de Lacerda - ja mencionado anteriormente - ao mesmo tempo que satiriza aquilo que era entendido como "inversão de papéis" ao esteriotipar as mulheres com trejeitos masculinos e põe os homens em submissão e assumindo as "tarefas femininas".

\footnotetext{
${ }^{43}$ HAHNER, June. Emancipação do Sexo Feminino. p. 156.

${ }^{44}$ Discurso de Assis Brasil, reformador da República. In: PINTO, Céli Regina Jardim. Uma história do Feminismo no Brasil, p. 29.

${ }^{45}$ PERROT, Michelle. As Mulheres Públicas. São Paulo: Unesp, 1998. p. 129-130.

46. PERROT, Michelle. As Mulheres Públicas p. 130

${ }^{47}$ Revista ilustrada semanal, que circulou no Rio de Janeiro de 1902 à 1953. Sua principal característica era a sátira política e o humor a partir de Charges.
} 


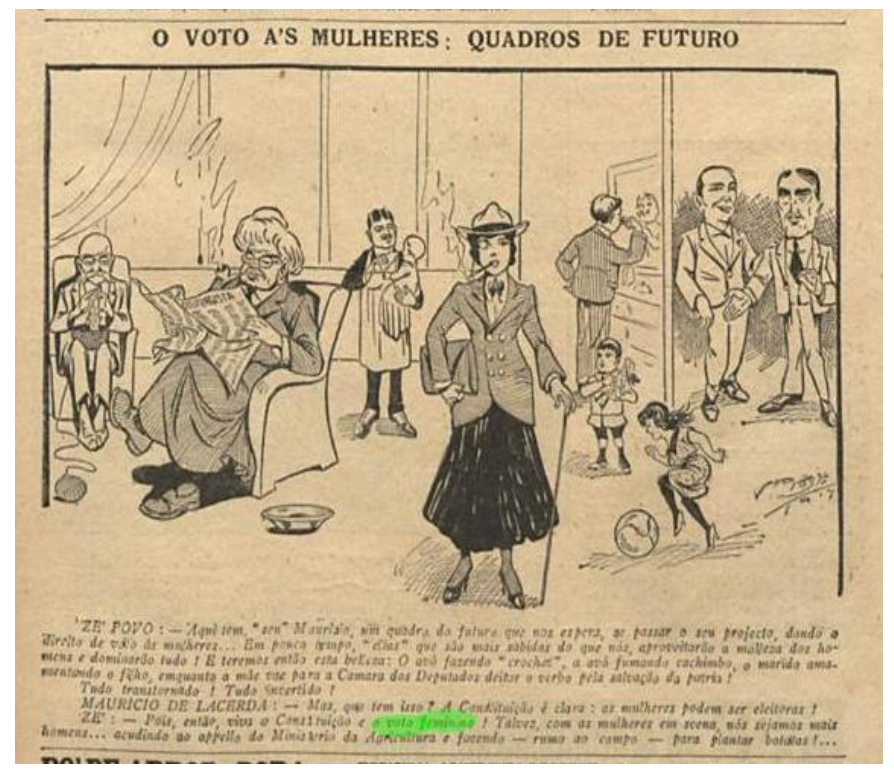

Diz a legenda:

ZÉ POVO: - Aqui tem, "seu” Mauricio, um quadro do futuro que nos espera se passar o seu projecto, dando o direiro de voto ás mulheres... Em pouco tempo. "ellas" que são mais sabidas do que nós, aproveitarão a moleza dos homens e dominarão tudo! E teremos então esta belleza: O avô fazendo "crochê", a avó fumando cachimbo, o marido amamentando o filho, enquanto vae para a Camara dos Deputados deitar o verbo pela salvação da pátria!

Tudo transformado! Tudo invertido!

MAURICIO DE LACERDA: - mas que tem isso? A Constituição é clara: as mulheres podem ser eleitoras!

ZÉ POVO: - pois então, viva a Consttiuição e o voto feminino! Talvez com as mulheres em scena, nós sejamos mais homens... acudindo ao appello do Ministério da Agricultura e fazendo - rumo ao campo - para plantar batatas! 48

No Amazonas não era diferente. Diversos segmentos da imprensa amazonense da época não fugiram à regra e externaram por vezes, uma postura preocupante, conflituosa e contraditória quando se referia às questões relacionadas à emancipação feminina, especialmente o sufrágio. Como exemplo dessa assertiva temos o artigo "A Proletária e o Feminismo", publicado no jornal Construtor Civil (1920). Nele, as mulheres trabalhadoras são aconselhadas a ficar longe da "aberração do século" chamada de feminismo e a se manterem fiéis à sua natureza.

a moderna aspiração da mulher que quer adquirir o chamado direito de voto, em modificar o processo do casamento, applaudindo o problema do divorcio e bem assim concorrer ás funcções publicas para cargos puramente masculinos, agora outras pretenções de somenos é o que constitue o feminismo. O eterno e inconteste prestígio da mulher sobre o homem fez que ele também se vá, sem reflexão, imbuindo-se dessas ideas collaborando-lhe nos desejos e concorrendo

${ }^{48}$ O Malho (RJ) Ed. 0771 de 23/06/1917. Disponível on line na Hemeroteca Digital da Biblioteca Nacional. 
assim, para a expansão, até certo ponto prejudicial dessa aberração do século. ${ }^{49}$

No tocante à luta pelo direito ao voto desempenhada pelas mulheres, esta é percebida pelo mesmo artigo como sendo uma nova "aberração" que não deveria ser levada em consideração, sendo tratada com pouca importância. Por esta concepção as mulheres, na verdade, pouco tempo teriam para se importar com política dado aos seus muitos afazeres, e se o fizesse seria apenas por influência de "trêfegos revolucionários" que a sociedade moderna ainda não havia conseguido se desvencilhar.

Deixai legislarem sobre liberdade de votos para a mulher. Essa nova aberração não lhe terá sequer a complacência tão múltiplos e nobres são seus afazeres para preoccupar-se com aquella velharia legada pelo militarismo do qual a sociedade moderna governada por trêfegos revolucionários, ainda não lhe poude desvenciliar. E assim irá ella marchando, recatada seu triumpho social, retraída na victoria diuturna da melhoria moral da espécie. Resistindo aos embates de todas as resoluções, ella affirma-se, cada vez mais no seu natural determinismo de filha, esposa e mãe. ${ }^{50}$

$\mathrm{O}$ assunto era tratado muitas vezes de forma leviana e preconceituosa, e tinha o propósito de ridicularizá-las, mesmo em veículos com posturas políticas mais sérias e respeitadas, como era o caso do Jornal do Commércio. Vejamos o exemplo a seguir transcrito no diálogo abaixo:

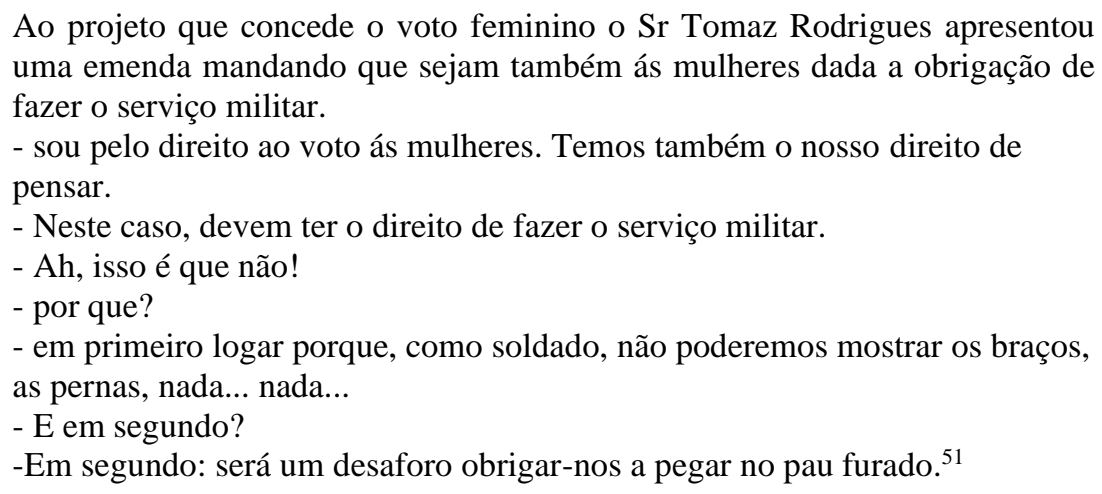

Embora esse tipo de discurso fosse o mais comum na imprensa da época mesmo assim, algumas vozes se levantaram em prol da defesa da mulher e de suas lutas. O jornal A Reacção, “órgão dos moços católicos de Manaus”, (1933), pleiteava que à elas fossem dado direitos políticos porque "se democracia é o governo do povo para o povo tão povo

\footnotetext{
49 O Constructor Civil, no 1 . Manaus, 5 de janeiro de 1920. In: PINHEIRO, Luís Balkar Sá Peixoto e PINHEIRO, Maria Luiza Ugarte (Orgs). Imprensa Operária no Amazonas. Manaus: EDUA/Cnpq, 2004, p. 119.

${ }^{50}$ PINHEIRO, Luís Balkar Sá Peixoto e PINHEIRO, Maria Luiza Ugarte (Orgs). Imprensa Operária no Amazonas. p.119

${ }^{51}$ Jornal do Commercio, 19 de novembro de 1927. Em várias edições da coluna "Uma Por Dia”, publicadas no Jornal do Commercio em meados da década de 1920, o alvo de críticas foram as reivindicações femininas bem como as suas mudanças comportamentais.
} 
são as mulheres como os homens" ${ }^{2}$. Representando os posicionamentos católicos, $A$ Reacção mostrou um discurso religioso progressista em relação às reivindicações femininas. Além de defenderem o direito feminino de votar e de poder ser votada, o referido jornal também não considerava o feminismo como um mal social, uma "aberração" como muitos o faziam, antes, procuravam entendê-lo como sendo resultado direto do progresso:

a mulher tem pleno direito não só a participação indireta no governo dos povos mediante o voto ativo de eleger seus candidatos ás Altas Câmaras da Nação, sinão também a participacção direta, mediante o voto passivo de poder ser eleita para ocupar uma cadeira em diversos cargos.

[...]Para muitos catholicos - e não católicos - o feminismo é pedra de escândalo. "A missão da mulher é a casa e a família", dizem.

Porém essa objeção perdeu todo o seu valor, desde que o industrialismo moderno lançou fora de casa ao quarenta ou cincoenta por cento das mulheres na idade de exercerem o sufrágio. Não se considera que, para ter sua casa, a mulher tem que sair a trabalhar fóra dela, nem se atende a que, mediante o voto, poderá melhorar as condições em que a colocou o industrialismo moderno..$^{53}$

Mas as sufragistas brasileiras também buscavam ampliar seus discursos na imprensa no intuito de organizar a luta pelo voto feminino e conseguir adesão popular. Josefina Azevedo, Bertha Lutz e muitas outras redatoras e colaboradoras da imprensa periódica da época, empenharam-se, categoricamente, em apresentar e discutir, por meio da imprensa, as propostas desse movimento às mulheres no Brasil.

Josefina Azevedo era bastante conhecida pois era muito atuante na imprensa do final do século XIX. Dirigia o Jornal A Família ${ }^{54}$, que começou a circular em 1888 consolidando-se como importante espaço de luta pela emancipação e pelos direitos das mulheres, especialmente a educação e o voto. Segundo análise de Teresa Marques, o periódio "foi pensado para atuar como plataforma da campanha pelo sufrágio e pela consciência política das mulheres" ${ }^{\circ 5}$. Em um artigo expressando sua opinião sobre a recusa ao alistamento eleitoral feminino, Josefina escreveu:

O fundamento universal de todos os que opinam contra a nossa emancipação é esse - que a mulher não tem capacidade política. Porque? Perguntamos nós, e a essa pergunta não nos dão resposta cabal. Em geral, os casos de incapacidade política são estes - menoridade, demência, inabilitações, restrição

\footnotetext{
52 A Reacção. Manaus, 2 de abril de 1933.

${ }^{53}$ A Reacção. Manaus, 2 de abril de 1933

${ }^{54} \mathrm{O}$ jornal A Família trazia em sua epígrafe: “jornal literário dedicado à educação da mãe de família”. Era de publicação semanal e cotava com oito páginas. Inicialmente o Jornal foi publicado em São Paulo e a partir de 1889 passou a circular no Rio de Janeiro devido a mudança de endereço de Josefina Azevedo. O Jornal teve duração até 1898. O Periódico encontra-se disponível digitalizado na Hemeroteca Digital da Biblioteca Nacional.

55 MARQUES, Teresa Cristina de Novaes. O Voto feminino no Brasil. $2^{\circ}$ ed. Brasília: Câmara dos Deputados , Edições Câmara, 2019. p. 62
} 
de liberdade por pena cominada, etc. etc. A esses aduzem os legisladores a "diferença de sexo". Mas em que essa diferença pode constituir razão de incapacidade eleitoral? A mulher educada, instruída, em perfeito uso de suas faculdades mentais, exercendo com critério as suas funções na sociedade, é uma personalidade equilibrada, apta para discernir e competente para escolher entre duas ideias aquela que melhor convém. Não pude por conseguinte estar em pé de igualdade com os dementes, com os menores, com os imbecis. Assim sendo, é absurdo o principio de sua incapacidade eletiva ${ }^{56}$.

Outro exemplo aqui destacado é um artigo da carioca Maria Sabina publicado na Revista Cabocla (1936) denominado de "Victorias do Feminismo". Neste artigo, a vicepresidente da FBPF defende vigorosamente o feminismo, conclamando saudosamente as mulheres amazonenses a conhecê-lo e defende um maior participação feminina nas lutas que se faziam necessárias, incluindo a participação na política.

Minhas amigas e companheiras de ideal.

É a vós especialmente que me dirijo neste momento em que, procurando esquecer a minha personalidade de escritora e artista creadora de emoções, quero ser simplesmente a colaboradora ardente e convicta, orientadora da opinião em tudo o que se relaciona com a causa feminina. Como vicepresidente da "Federação Brasileira Para o Progresso Feminino", a maior organização feminina brasileira (..), creio ter alguma autoridade como orientadora da opinião. O Grito angustioso da mulher que desde o século passado vem repercutindo até nós encontrou um eco de simpatia em nosso país até os seus recantos longínquos como o prova neste momento a nossa ramificação amazonense em cujo seio acolhedor e amigo me encontro neste momento encantada e desvanecida. A Federação Amazonense Pelo Progresso Feminino "é uma destas árvores novas douradas pelo sol dos trópicos"(...).

$\mathrm{Na}$ opulência da sua grandeza a Amazônia é uma virgem. E muitas almas aqui serão como o solo generoso que ainda não foi desbravado e semeado de idéias novas em respeito de verdades básicas do feminismo. Nelas, a semente da justiça e de Beleza da causa da mulher, germinará na exuberância primitiva de um deslumbrante florescimento tropical. Mas, se não necessitamos da ardência devoradora das queimadas, faz-se, contudo, mister a derrubada dos preconceitos. $\mathrm{O}$ feminismo ainda representa para muitos uma anormalidade, uma doutrina que prega o antagonismo dos sexos, e um nivelamento, uma espécie de masculinização que representa a perda de toda a graça e feminilidade da mulher.

Nada mais falso. Pelo menos concordareis, inicialmente que, apesar de ter atingido os mais altos postos no Feminismo Nacional, que não me parece com este retrato pessimista e não renunciei aos mesmos requisitos femininos. Quanto ao mais, a boa e sã doutrina feminista não pode nem quer considerar o homem como inimigo e adversário e sim como colaborador. Em alguns casos é o homem que se recusa á "intente cordiale" que terá que finalmente prevalecer. O feminismo não é uma anomalidade, uma extravagância contemporânea, um fruto adventício da época todado a desaparecer. É antes uma consequiência moral da macha das civilizações. ${ }^{57}$

${ }^{56}$ A Família, 21 de Dezembro de 1889.

${ }^{57}$ Revista Cabocla. Manaus, 1936 


\section{Enfim a vitória!}

De maneira isolada ainda na década de 1920, alguns Estados brasileiros permitiram o alistamento eleitoral feminino. Em 1927, de forma pioneira, o Estado do Rio Grande do Norte, seguido por Minas Gerais no mesmo ano e em 1929, o Rio de Janeiro. No entanto, cabia à justiça conceder ou não o direito ${ }^{58}$. No Rio Grande do Norte,

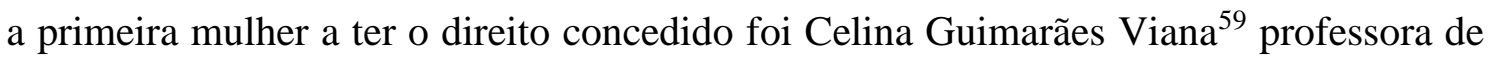
Mossoró. Ela se tornou oficialmente a primeira eleitora do Brasil no ano de $1927^{60}$. No mesmo Estado, no ano seguinte, a cidade de Lajes elegeu a primeira representante do poder executivo do Brasil e da América Latina, Alzira Soriano, que foi eleita para o cargo de prefeita com $60 \%$ dos votos ${ }^{61}$.

Através do Decreto $\mathrm{n}^{\circ}$. 21.076, de 24 de fevereiro de $1932^{62}$, após intensa e longa campanha nacional, e de grandes debates sobre o pré-projeto elaborado no ano anterior, o sufrágio finalmente foi estendido às mulheres em todo o país ${ }^{63}$. Foi assinado pelo presidente Getúlio Vargas, afirmando que era eleitor o cidadão maior de 21 anos, sem distinção de sexo, alistado na forma do código ${ }^{64}$ e sem as restrições que estavam previstas no pré-projeto ${ }^{65}$. Apesar da conquista e da instituição do voto amplo às mulheres, a crítica que se faz ao código é que ele determinou como facultativo o alistamemento feminino “ talvez por considerarem que as brasileiras não iram mesmo se interessar em participar das

\footnotetext{
${ }^{58}$ Informações preliminares da pesquisa apontam que antes do Código eleitoral de 1932, dez estados brasileiros permitiam o alistamento eleitoral feminino. No entanto, além dos três citados, não conseguimos localizar ainda quais eram os outros Estados. Esperamos obter essa resposta no decorrer na pesquisa.

${ }^{59}$ Celina conseguiu o reconhecimento de seu direito por meio da lei estadual 660/1917, na qual constava a possibilidade do voto feminino. Consta no art. 77 da referida lei: "No Rio Grande do Norte poderão votar e ser votados, sem distincção de sexos, todos os cidadãos que reunirem as condições exigidas por esta lei.". Fonte: www.migalhas.com.br

${ }^{60}$ Pinto, Céli Regina Jardim. Uma História do Feminismo no Brasil., p. 25. No entanto, uma informação de Branca Moreira Alves (Ideologia e feminismo. Petrópolis: Vozes, 1980. p. 94-95) é a de que, muito antes, no ano de 1906, na comarca de Minas Novas, Minas Gerais, três mulheres, Alzira Vieira Ferreira Netto, mais tarde formada em Medicina, Cândida Maria dos Santos, professora em escola pública, e Clotildes Francisca de Oliveira, haviam já se alistado como eleitoras e votado.
}

${ }^{61}$ Segundo fontes preliminares da pesquisa, Alzira Soriano foi impedida de exercer o mandato pois teve seus votos anulados pela Comissão de Poderes do Senado.

${ }^{62}$ Além do Voto feminino, o código de 1932 também instituiu o voto secreto e a criação da Justiça eleitoral.

${ }^{63}$ Os primeiros países a concederem esse direito foram a Nova Zelândia, em 1893 e Finlândia em 1906, seguido por Inglaterra em 1918, EUA em 1920. O Equador foi o primeiro país latino-americano a permitir que suas cidadãs votassem, em 1929. Os últimos países a aprovar o sufrágio feminino foram África do Sul em 1993 e Arábia Saudita em 2011.

${ }^{64}$ Texto contido no artigo $2^{\circ}$ do Decreto.

${ }^{65} \mathrm{~A}$ saber: pretendia estabelecer o voto às mulheres casadas com autorização do marido e às solteiras ou viúvas que tivessem renda própria. 
lides eleitorais", como analisou Karawejczyk. ${ }^{66}$

Conquistado o direito a partir do código eleitoral de 1932, o grande desafio das sufragistas a princípio foi o de obter a participação das mulheres nas eleições, tanto como eleitoras como também candidatas aos cargos políticos pois interessava poder votar e ser votada, interessava transpor barreiras, conquistar representatividade nas Tribunas e continuar lutando por mais direitos e igualdade para as mulheres. Posteriormente as mobilizações e luta continuaram para garantir que esse direito fosse ratificado na próxima Constituição que seria elaborada.

Nas eleições para a Assembleia Nacional Constituinte de 1933 as brasileiras que atendiam aos requisitos legais usufruiram do seu direito de votar e serem votadas e até eleitas em cargos políticos em todo o Brasil, como é o caso da médica Carlota Pereira de Queiroz, eleita primeira deputada brasileira, e da própria Bertha $\mathrm{Lutz}^{67}$.

Em 1934, com a nova Constituição, foi confirmado o voto feminino (art 108) estabelecido pelo Código de 1932, no entanto, só as mulheres que exercessem funções remuneradas em cargos públicos eram obrigadas a votar (art. 109) . A obrigatoriedade do voto para todas as mulheres só foi estabelecida no artigo 131 da Constituição de 1946.

Falemos um pouco sobre o cenário local. A primeira representante feminina na política estadual amazonense foi eleita por voto popular, inclusive feminino, em $1934^{68}$, portanto apenas dois anos depois da publicação do código de 1932. Maria de Miranda Leão foi eleita para o cargo de deputada estadual na Assembléia Constituinte, pelo Partido Socialista, tomando posse em 3 de junho de 1935. A Mãezinha como era conhecida, teve sua vida dedicada às causas sociais: fundou a Sociedade de Amparo à Maternidade e Infância em 1922; o Hospital Infantil Dr. Fajardo, o serviço para crianças recém-nascidas de pais hansenianos e era diretora de dois abrigos infantis. De família tradicional na sociedade amazonense, Maria de Miranda Leão ingressou na vida pública do Amazonas em 1922, no serviço de Profilaxia rural e é considerada a primeira assistente social do Amazonas. No período anterior à sua eleição liderou o movimento feminino católico de incentivo a participação das mulheres nas eleições e na política de modo geral, fato que

\footnotetext{
${ }^{66}$ KARAWEJCZYK, Mônica. A mulher deve votar?O código eleitoral de 1932 e a conquista do voto feminino através das páginas dos jornais Correio da Manhã e A Noite. p.225

${ }^{67}$ Carlota foi eleita com 176 mil votos no Estado de São Paulo. Foi a primeira mulher constituinte a assinar uma Constituição (a de 1934). Bertha Lutz, representando a Liga Eleitoral Independente, instituição criada por ela e ligada ao movimento feminista, conquistou a primeira suplência, tomando posse em 1936, em consequência da morte do deputado constituinte Cândido Pessoa. Fonte: www.tre-rs.jusbrasil.com.br ${ }^{68}$ Quatro décadas depois, em 1978, Eunice Mafalda Michilles foi eleita suplente do senador João Bosco Ramos de Lima, porém em Maio de 1979 com o falecimento de João Bosco assumiu a vaga aberta no Senado, tornando-se assim a primeira senadora do país.
} 
certamente muito contribuiu para seu sucesso nas urnas aos 48 anos. Além dos trabalhos voltados para a assistência aos menos favorecidos, principalmente para crianças e mulheres, Maria de Miranda Leão era participante ativa do Movimento sufragista, sendo membro da Federação Feminista Amazonense e uma das fundadoras da Federação Brasileira pelo Progresso Feminino. Segundo análise de Maria das Graças Costa, os pronunciamentos da Mãezinha no legislativo estavam voltados principalmente em defesa da Igreja Católica, pela valorização da mulher amazonense, pela inclusão do ensino religioso nas escolas ${ }^{69}$ e contra aquilo que ela considerava como a maior ameaça ao Brasil: o comunismo. A autora sugere ainda que a deputada era vítima de preconceito tanto por parte dos colegas de Plenário, a quem deveria incomodar pelos seu pioneirismo, como também por parte da imprensa da época que sempre noticiavam seu desempenho na Assembléia de forma jocosa, destacando o a suposta fragilidade feminina: "a casa, que estava acostumada ao cachoeirar das vozes masculinas, precisava ser benevolente para se aperceber do sussurro da voz feminina" ${ }^{\text {70 }}$. Mesmo assim, a autora reitera que,

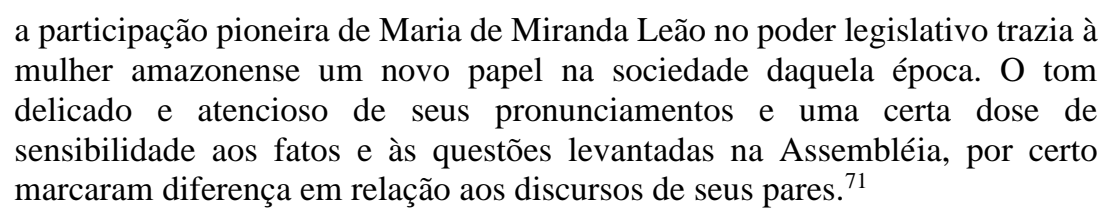

Como deputada estadual, Maria de Miranda Leão, representou oficialmente o Estado em diversos congressos, inclusive nos Femininos. Exemplo disso é a sua participação como oradora e delegada no $3^{\circ}$ Congresso Nacional Feminino, realizado pela Federação Brasileira pelo Progresso Feminino (FBPF) em outubro de 1936 no Rio de Janeiro. Terminado o seu mandado, a Mãezinha continuou atuando nos serviços de assistência social, só tentando novo ingresso na vida política no ano de 1947, pelo Partido Social Democrático (PSD), porém não obtendo êxito. Em 1969, com 82 anos de idade, dos quais 47 foram dedicados aos cuidados dos mais pobres, recebeu da Prefeitura de Manaus a 'Medalha Cidade de Manaus'. Faleceu no Rio de Janeiro, em 16 de fevereiro de 1976 aos 89 anos.

\footnotetext{
${ }^{69}$ COSTA, Maria das Graças Pinheiro da. O Direito à educação no Amazonas (1933-1935). Tese de Doutorado. Belo Horizonte: UFMG, 2001, p. 216

${ }^{70}$ O Jornal. Manaus, 27/02/1935. In: COSTA, Maria das Graças Pinheiro da. O Direito à educação no Amazonas (1933-1935).p. 216

${ }^{71}$ COSTA, Maria das Graças Pinheiro da. O Direito à educação no Amazonas (1933-1935). p.216
} 
Imagem 2

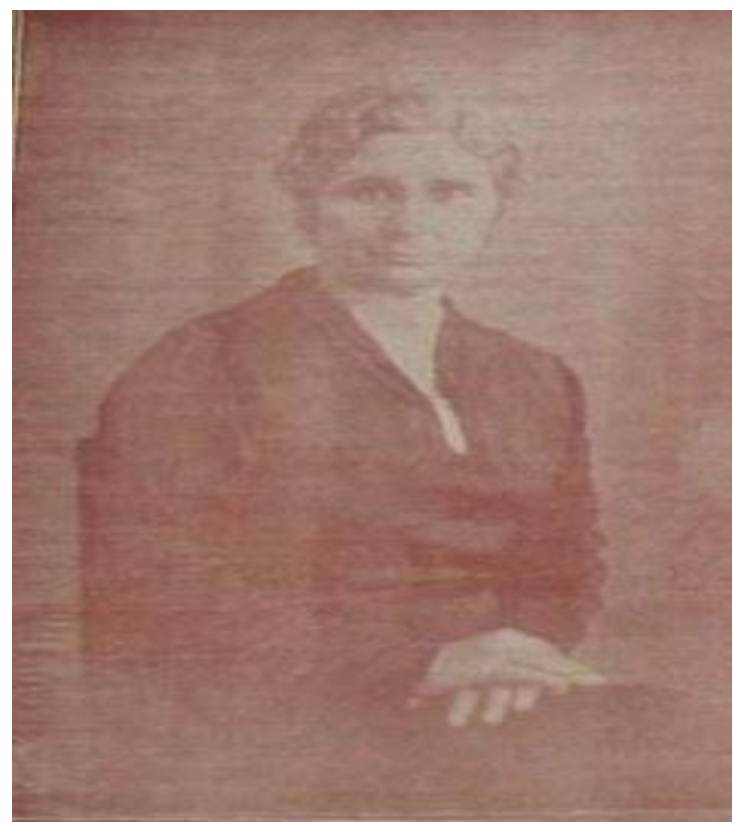

Maria de Miranda Leão. Fonte: Revista Cabocla. Manaus, Fevereiro de 1936

Somente em 1985, a última barreira exitente em relacão ao voto feminino caiu, quando a Emenda Constitucional no 25 de 15 de maio de 1985, permitiu o voto dos analfabetos no Brasil. Com essa última barreira derrubada, cerca de 27,1\% das mulheres analfabetas existentes no país na década de 1980, segundo dados do IBGE, puderam usufruir do direito conquistado em 1932. ${ }^{72}$

Passados 88 anos da conquista do direito ao voto e da elegibilidade, a luta pela maior participação feminina continua. Embora as mulheres representem 52\% do eleitorado do pleito de 2018, ainda é muito pequeno o número de mulheres que solicitaram seu registro de candidatura à Justiça Eleitoral. Segundo a ministra e presidente do TSE, Rosa Weber, "há uma verdadeira sub-representação feminina na política brasileira, sem falar nas candidaturas 'laranjas', fantasmas ou fictícias de mulheres que não tiveram um voto sequer, nem o delas mesmas"73. É necessário, portanto, que as mulheres participem mais da política brasileira, ajudando a fortalecer o Estado Democrático de Direito e compreenda que mudanças significativas nos direitos para as mulheres dependem de termos mais representantes nos poderes legislativo e executivo.

Data de submissão: $28 / 04 / 2020$

Data de aceite: 10/06/2020

\footnotetext{
72 . Disponível em www.tse.jus.br. Acesso em 28/12/19.

73 Seminário "Elas por elas", Brasília, 2018. Disponível em www.tse.jus.br/imprensa. Acessado em 22/08/19
} 


\section{Referências Bibliográficas}

ALVES, Branca Moreira. Ideologia e feminismo: a luta pelo voto no Brasil. Petrópolis: Vozes, 1980.

BESTER, Gisela Maria. A luta sufrágica feminina e a conquista do voto pelas mulheres brasileiras: aspectos históricos de uma caminhada. Argumenta Journal Law, Jacarezinho - PR, Brasil, n. 25. p. 330-333.

BORELLI, Andrea. “A Rainha do Lar”. A esposa e a mãe perante a legislação brasileira. 1830-1950. Anais do XVIII Encontro Regional de História - O historiador e seu Tempo. ANPUH/SP - UNESP/Assis, 24 a 28 de julho de 2006.

CAMPOS, Luciane Maria Dantas de. Trabalho e Emancipação: um olhar sobre as Mulheres de Manaus (1890-1940). Dissertação de Mestrado. UFAM, 2010.

Código Eleitoral, 1932. Disponível em www.tse.jus.br

Constituição da República Federativa do Brasil, 1891. Disponível em www.planalto.gov.br

Constituição da República Federativa do Brasil, 1934. Disponível em www.planalto.gov.br

Constituição da República Federativa do Brasil, 1946. Disponível em www.planalto.gov.br

COSTA, Maria das Graças Pinheiro da. O Direito à educação no Amazonas (19331935). Tese de Doutorado. Belo Horizonte: UFMG, 2001.

HAHNER, June. E. A luta pelos direitos da mulher no Brasil, 1850-1940. Florianópolis: Editora Mulheres/EDUNISC, 2003. p.160

HAHNER, June. A Mulher Brasileira e Suas Lutas Sociais e Políticas: 1850-1937. São Paulo: Brasiliense, 1981.

KARAWEJCZYK, Mônica. A mulher deve votar?O código eleitoral de 1932 e a conquista do voto feminino através das páginas dos jornais Correio da Manhã e A Noite. $1^{\circ}$ ed. Jundiaí, SP: Paco, 2019.

KARAWEJCZYK, Mônica. As filhas de Eva querem votar. Dos primórdios da questão à conquista do sufrágio feminino no Brasil (c.1850-1932). Tese Doutorado em História. Universidade Federal do Rio Grande do Sul, Porto Alegre, 2013.

KARAWEJCZYK, Mônica. O Feminismo em Boa Marcha no Brasil! Bertha Lutz e a Conferência pelo Progresso Feminino. Revista Estudos Feministas, Florianópolis, 26(2) Disponível em www.periodicos.ufsc.br

KARAWEJCZYK, Mônica. "O voto e as saias": as repercussões do projeto Lacerda sobre o alistamento feminino (1917). Revista Altos e Baixos, 2015.p.72. Disponível em: http://revistadigital.jfrs.jus.br/revista/index.php/revista_autos_e_baixas

LEITE, Carlos Henrique Ferreira. Teoria, metodologia e possibilidades: os jornais como fonte e objeto de pesquisa histórica. ESCRITAS Vol. 7 n.1 (2015) ISSN 2238-7188 p. 3-17.

MALUF, Marina e MOTT, Maria Lucia. “Recônditos do Mundo Feminino”. In: História 
da Vida Privada no Brasil. Vol 3. República: da Belle époque à era do Rádio. São Paulo: Cia das Letras, 1998.

MANCILHA, Virginia Maria Netto, Vozes femininas: um estudo sobre a Revista Feminina e a luta pelo direito ao voto, ao trabalho e à instrução. Dissertação de mestrado - UNICAMP, 2012;

MARQUES, Teresa Cristina de Novaes. O Voto feminino no Brasil. $2^{\circ}$ ed. Brasília: Câmara dos Deputados , Edições Câmara, 2019.

MOURELle, Rodrigo Cavaliere et al. A Federação Brasileira pelo Progresso Feminino e o governo de Getúlio Vargas na década de 1930: estratégias e paradoxos do movimento feminista no Brasil. Colóquio Internacional Gênero, Feminismos e Ditaduras no Cone Sul. Universidade Federal de Santa Catarina - de 4 a 7 de maio de 2009

NAZÁRIO, Diva Nolf. Voto feminino \& feminismo. São Paulo: Imprensa Oficial, 2009.

PERROT, Michelle. As Mulheres Públicas. São Paulo: Unesp, 1998.

PINHEIRO, Luís Balkar Sá Peixoto e PINHEIRO, Maria Luiza Ugarte (Orgs). Imprensa Operária no Amazonas. Manaus: EDUA/Cnpq, 2004

PINTO, Celi Regina. Uma história do Feminismo no Brasil. São Paulo: Editora Fundação Perseu Abramo, 2003

SANTOS, Luiza Chaves. Sufrágio Feminino e democracia no Brasil. Monografia de conclusão do Curso de Direito. PUC/RIO, Rio de Janeiro, 2017.

SILVA. Lenina Vernucci da. Gênero e Poder: Diva Nolf Nazário na luta pelo voto feminino. Dissertação de Mestrado. UNESP Araraquara, 2014

SOIHET, Rachel. "Transgredindo e conservando, mulheres conquistam o espaço público: a contribuição de Bertha Lutz. Labrys - estudos feministas. Brasília, v.2, nº 1, julhodezembro 2002.

SOUTO-MAIOR, Valéria Andrade. O florete e a Máscara. Josefina Álvares de Azevedo. Dramaturga do Século XIX. Florianópolis: Mulheres, 2001.

TOSCANO, Moema; GOLDENBERG, Miriam. A Revolução das Mulheres: um balanço do feminismo no Brasil. Rio de Janeiro: Revan, 1992. 